\title{
Marxismo, campesinado y economía moral en la historiografía mexicana ${ }^{1}$
}

\section{Marxism, peasants and moral economy in mexican historiography}

\author{
Jesús Iván Mora Muro* \\ UNIVERSIDAD AUTÓNOMA DE QUERÉTARO \\ http://doi.org/10.22370/pe.2020.10.2662
}

\section{RESUMEN}

En el presente texto se exploran las implicaciones de la paulatina transformación de la historiografía mexicana en torno a los estudios sobre el campesinado y sus formas de resistencia ante el embate capitalista. Se argumenta que de una historia marxista (economicista) se pasó a una de tintes más culturalistas (historia social y después a la historia subalterna). Sin embargo, estas nuevas tendencias historiográficas se aplicaron de manera muy tardía en el ámbito mexicano. En general, todavía hacia finales de los años ochenta fue patente la fuerte resistencia al cambio de paradigma impuesto por el marxismo ortodoxo, que dificultó la incorporación de la teoría social para el estudio de las clases subordinadas cuyos representantes más importantes fueron E. P. Thompson, Eric Hobsbawm, Lawrence Stone, entre otros. La investigación complementa los balances historiográficos que durante los últimos ańos se han elaborado sobre el tema. Principalmente, destacan los trabajos de Eric van Young, Leticia Reina, Mary Kay Vaughan y Peter Guardino, quienes han privilegiado en su análisis las obras elaboradas por historiadores y se han olvidado de los teóricos sociales que se dedicaron al tema campesino desde perspectivas antropológicas como Roger Bartra, Arturo Warman, entre otros.

Palabras claves: Marxismo, campesinado, historiografía mexicana, historia social.

\begin{abstract}
This text explores the implications of the gradual transformation of Mexican historiography around studies about the peasantry and their forms of resistance to the capitalist onslaught. It is argued that from a Marxist history (economist) it was passed to one of more culturalist type (social history and later to subaltern history). However, these new historiographic trends were applied very late in the Mexican environment. In general, still towards the end of the eighties, the strong resistance to the paradigm shift imposed by orthodox Marxism was evident, which made it difficult to incorporate social theory for the study of the subordinate classes, whose most important representatives were E. P. Thompson, Eric Hobsbawm, Lawrence Stone, among others. The research complements the historiographic balances that have been elaborated on the subject in recent years. Mainly, the works of Eric van Young, Leticia Reina, Mary Kay Vaughan and Peter Guardino stand out, who have privileged in their analysis the works prepared by historians and have forgotten of the social theorists who dedicated themselves to the peasant subject from anthropological perspectives, such as Roger Bartra, Arturo Warman, among others.
\end{abstract}

Keywords: Marxism, peasantry, Mexican historiography, social history

*jesus.mora@uaq.mx 


\section{INTRODUCCIÓN}

En el presente texto se exploran las implicaciones de la paulatina transformación de la historiografía mexicana en torno a los estudios sobre el campesinado y sus formas de resistencia ante el embate capitalista. Se argumenta que de una historia marxista dura (economicista) se pasó a una de tintes más culturalistas (historia social y después a la historia subalterna). Sin embargo, estas nuevas tendencias historiográficas se aplicaron de manera muy tardía en el ámbito mexicano. En general, todavía hacia finales de los años ochenta fue patente la fuerte resistencia al cambio de paradigma impuesto por el marxismo ortodoxo, que dificultó la incorporación de la teoría social para el estudio de las clases subordinadas cuyos representantes más importantes fueron E. P. Thompson, Eric Hobsbawm, Lawrence Stone, entre otros. La investigación complementa los balances historiográficos que durante los últimos años se han elaborado sobre el tema. Principalmente, destacan los trabajos de Eric van Young, Leticia Reina, Mary Kay Vaughan y Peter Guardino, quienes han privilegiado en su análisis las obras elaboradas por historiadores y se han olvidado de los teóricos sociales que se dedicaron al tema campesino desde perspectivas antropológicas como Roger Bartra, Arturo Warman, entre otros.

He decidido utilizar el término "resistencia campesina", en lugar del de "rebelión campesina" que, aunque ha sido ampliamente utilizado por los estudiosos del tema, designa o se refiere a actos de violencia generalizada. En cambio, el de "resistencia" incluye, de manera más amplia, los estudios sobre la ruralidad en México y sus manifestaciones de inconformidad social no necesariamente armadas. En la categoría historiografía mexicana se incluyen las investigaciones de autores extranjeros, norteamericanos principalmente, que se han dedicado al estudio de los movimientos sociales en México y, particularmente, de las rebeliones campesinas. Debido a los estrechos vínculos que se han ido consolidando desde los años setenta entre las ciencias sociales y las humanidades en México, el estudio también incorpora el análisis de algunas obras de antropólogos y sociólogos que contribuyeron, de manera importante, al mantenimiento, pero 
también a la transformación, del paradigma interpretativo marxista que permeó las indagaciones sobre el campo mexicano y sus actores durante la segunda mitad del siglo XX.

\section{LOS DE ABAJO COMO PROBLEMA ${ }^{2}$}

Con la "historia desde abajo" protagonizada por George Rudé, Albert Soboul y E. P Thompson, se buscó desentrañar las acciones de las clases desposeídas en la vida cotidiana, la cultura de los trabajadores, sirvientes, mujeres, grupos étnicos desfavorecidos, etc. ${ }^{3}$

El interés historiográfico por las clases populares en el trabajo de Thompson se enmarca en una coyuntura historiográfica en donde el reconocimiento de lo cultural cuestionó la noción marxista de "clase". En The making of english working class, ${ }^{4}$ considerada una obra determinante en el inicio y desarrollo de la historia social inglesa, Thompson hizo hincapié en el papel que jugaba la experiencia (individual y colectiva) dentro del devenir histórico y reconoció el papel activo de la clase trabajadora en la construcción de la historia. Además, fue más allá de las interpretaciones exclusivamente economicistas en torno a la formación de la clase obrera:

Yo polemizaba contra esta noción para mostrar que existía una conciencia plebeya reflejada en nuevas experiencias de existencia social, las cuales eran manipuladas de forma cultural por la gente, dando origen a una conciencia transformada. ${ }^{5}$

Es patente que, desde la óptica thompsoniana, la esfera cultural debía tomar un papel preponderante en los estudios sobre la identidad de la clase obrera. A través de su apelación a las costumbres y al fundamento moral de la economía, enfatizó la importancia del comportamiento cotidiano representado en el teatro, en las fábricas, en los motines, es decir, en todas aquellas actividades masivas susceptibles de encontrar lo simbólico. También el estudio de los rituales le permitió capturar las representaciones normativas implícitas en la conducta colectiva y el rompimiento, no directo en la mayoría de las ocasiones, con el poder establecido. Dicho de 
otra manera, el ritual podía ser un observatorio privilegiado para el estudio simbólico de la vida política, social y doméstica de las masas. En este proceso interpretativo, la antropología significó para Thompson la consolidación de una nueva visión:

El estimulo antropológico no surte su efecto en la construcción de modelos, sino en la localización de nuevos problemas, en la percepción de problemas antiguos con ojos nuevos, en el énfasis sobre normas o sistemas de valores y rituales, en la atención a las funciones expresivas de las diversas formas de motín y revuelta, y en las expresiones simbólicas de la autoridad, el control y la hegemonía. ${ }^{6}$

La reconstrucción de la "textura de las relaciones domésticas y sociales" y el rescate del "inmenso grupo de los actores secundarios", fueron objetivos manifiestos que guiaron las preocupaciones de la historia social desde los años setenta. En cuanto a la interpretación de los campesinos, Thompson propuso examinar sus prácticas hereditarias, las dotes, el ciclo del desarrollo familiar, es decir, factores no necesariamente económicos o materiales, sino aspectos más cercanos al sentir popular. Es por esto que para él la economía sólo podía ser entendida dentro del contexto de una sociedad cuya urdimbre está formada por costumbres condicionadas por la vida doméstica. ${ }^{7}$ Así, la exaltación de la costumbre en las clases bajas constituyó la reivindicación de nuevos derechos y en la práctica significó un "campo de contienda", es decir, una forma de fundamentar la resistencia popular. ${ }^{8}$

En este sentido, su concepto de "economía moral" acuńado en 1971,9 surgió para explicar las resistencias de la clase obrera al avance de la economía de mercado. La economía moral fue concebida como una forma de equilibrar el poder económico capitalista mediante normas éticas que aseguran la justicia social. La evidencia de este tipo de economía puede encontrarse en prácticas como la asistencia, el trabajo comunal y en mecanismos que refuerzan la equidad económica. Consiste en un punto de vista tradicional de las normas y obligaciones sociales del propietario hacia la comunidad. 
La "historia desde abajo" se orientó al estudio de sujetos que antes simplemente eran considerados como objetos carentes de acción, víctimas de la explotación laboral, de la apropiación de recursos y de la dominación social. Se les reinterpretó como campesinos de subsistencia, pequeños productores de mercancías, consumidores, participantes en los mercados, luchadores por formas locales de poder, oficiantes religiosos, y, sobre todo, como "figuras de resistencia, revoltosos y rebeldes". ${ }^{10}$ Posteriormente, James Scott inició el estudio de los campesinos como actores económicos que se regían por "costumbres" que, muy frecuentemente, se oponían a la racionalidad económica capitalista.

The distinctive economic behavior of the subsistenceoriented peasant family results from the fact that, unlike a capitalist enterprise, it is a unit of consumption as well as a unit of production. The family begins with a more or less irreducible subsistence consumer demand, based on its size, which it must meet in order to continue as a unit. Meeting those minimal human needs in a reliable and stable way is the central criterion which knits together choices of seed, technique, timing, rotation, and so forth. ${ }^{11}$

El comportamiento económico del campesinado, en opinión de Scott, se caracterizaba por la búsqueda de la subsistencia y, en consecuencia, por evitar el riesgo que conlleva la maximización de utilidades. Así, Scott analizó las prácticas sociales campesinas, como la ayuda mutua, la relación entre patrón y cliente, o el uso comunal de la tierra, es decir, todas aquellas prácticas imbricadas en un universo moral en el que ocupan un lugar central la justicia y la equidad construidas en base al derecho y la subsistencia. ${ }^{12}$

De forma paralela, en Francia, bajo la batuta de los Annales, frente a una historia consagrada, durante los ańos sesenta y setenta, a la exploración de lo económico y lo social (con una metodología extraída de las ciencias exactas y demográficas), se inició un proceso de cambio en donde aparecieron nuevos objetos de estudio más 
cercanos a lo cultural o lo que se llegó a llamar "historia de las mentalidades". Para Jacques Le Goff, la historia de las mentalidades estudiaba lo cotidiano y lo automático, lo que escapaba a los sujetos individuales de la historia. ${ }^{13}$

Las actitudes ante la vida y la muerte, los ritos y las creencias, las estructuras de parentesco, las formas de sociabilidad, fueron algunas de las temáticas que el historiador, con ayuda de teorías antropológicas y sociológicas, inició durante los ańos setenta y ochenta. Sin embargo, la historia de las mentalidades no abandonó las enseñanzas que la historia serial y cuantitativa le había legado, es decir, el interés por las masas, por la cultura popular y el rescate de las colectividades. Esto es patente si tomamos en cuenta la influencia antropológica de Claude Levi-Strauss y Clifford Geertz, o los trabajos "cuantitativos" sobre la muerte y la "descristanización" hacia el siglo XVIII con una visión cultural de Michel Vovelle. ${ }^{14}$

\section{LA HISTORIA SUBALTERNA}

Las aportaciones de Thompson y Scott fueron determinantes para comprender desde otra mirada las motivaciones de las clases populares (obreros y campesinos). Estas ideas fueron aprovechadas por autores como Ranajit Guha y Dipesh Chakrabarty quienes iniciaron lo que se ha llegado a llamar la escuela poscolonialista. Herederos de la historia social, los poscolonialistas afirman que es necesario apartar el discurso dominante para acceder al discurso subalterno de manera no contaminada. Han insistido en el rescate -de forma no nacionalista o populista- de las huellas dejadas por las clases populares como sujetos de la historia, superando, de esta manera, la historia eurocentrista e historicista (teleológica) dominante. ${ }^{15}$

Ranajit Guha es claro al afirmar que los archivos gubernamentales, que habían sido para la historia social las fuentes más utilizadas para conocer a las clases populares, estaban marcados por los intereses del poder hegemónico. De esta manera, en su opinión, la construcción de los vestigios por parte del poder dominante impide acceder a las experiencias subalternas. Por ejemplo, las fuentes judiciales, 
invariablemente están mediadas por una autoridad (el juez) que es representante de este poder dominante. La historia subalterna, por lo contrario, busca llegar a un conocimiento de los actos en su simplicidad, en el momento de ocurrir. Es decir, su interés es preguntarse cómo actúan pragmáticamente los individuos ante las circunstancias, sin ser determinados por un acontecimiento que todavía no ocurre: una revolución, un crimen, un cambio de época, entre otros sucesos construidos a posteriori. ${ }^{16}$

Por su parte, Dipesh Chakrabarty, aunque reconoció los logros alcanzados por los estudios poscoloniales de los que él mismo había sido participe, aceptó que existen algunas puntos discutibles en los planteamientos de Guha. En su opinión, el más importante de los cuestionamientos a este tipo de historiografía es que ha pretendido ver en las acciones de los subalternos, y en el historiador mismo, una supuesta autonomía, totalmente apartada del poder hegemónico. ${ }^{17}$ ¿Quién es el sujeto de la historia? ¿Qué lineamientos historiográficos determinan al historiador en su discurso? Lo cierto es que el eurocentrismo sigue dominando las tendencias en las investigaciones de los pasados subalternos, incluyendo las que se han llamado historias indias, chinas, etc. El pensamiento europeo no ha dejado de crear "percepciones teóricas absolutas" o categorías de análisis con pretensiones universalistas. ${ }^{18}$

En Estados Unidos, la llamada New Cultural History se ha caracterizado desde los años noventa por el estudio de las "representaciones colectivas", cuyo objetivo es el abordaje de las estructuras mentales duraderas que motivan las conductas individuales o grupales y los sistemas simbólicos que emplea la gente para explicar el mundo que la rodea. Un segundo aspecto que la caracteriza es el creciente interés, aunque de ninguna manera exclusivo, por los grupos subordinados de la historia, es decir, por los subalternos. En este sentido, ¿Cuál es la diferencia básica entre la Historia Social y la Historia Cultural?

En opinión de Eric Van Young, la historia cultural, a diferencia de la historia social, intenta "deconstruir las formaciones hegemónicas que inciden en la producción y reproducción de los significados 
y los símbolos que los representan". Es decir, como la escuela poscolonialista lo afirma, es necesario apartar el discurso dominante para llegar al discurso subalterno "no contaminado", por decirlo de alguna manera. ${ }^{19}$

Un caso paradigmático, debido a la efervescencia de opiniones que ha despertado, es el de Florencia Mallon y su trabajo Campesinado y nación. ${ }^{20}$ El libro explora, a partir de dos procesos de resistencia regional y campesina en el marco de la lucha contra una invasión extranjera-México durante la intervención francesa y Perú durante la segunda guerra del Pacífico- el papel de los campesinos en la formación del Estado nacional. La propuesta de Mallon es tomar en cuenta la participación popular en la política decimonónica y no únicamente, como ha sido lo común, a las elites dirigentes.

La misma Florencia Mallon, consciente de sus propias influencias generacionales, se declara heredera de los cambios sufridos desde los años sesenta en el mundo occidental, principalmente estadounidense, que combinó una ascendente crisis del marxismo con el renacimiento del feminismo y el posestructuralismo. ${ }^{21}$ Así, guiada por el giro cultural y postcolonial, Mallon aborda al sujeto desde la perspectiva del "otro", que es entendido como distinto del grupo dominante y que no figura en los discursos hegemónicos.

La imagen teórica más utilizada es la de descentrar. Para tomar en serio la historia intelectual y cultural de los campesinos indígenas, debemos descentrar nuestros conceptos de intelectual y de comunidad. Para entender el papel de la gente subalterna en la historia, debemos descentrar nuestra visión en el proceso histórico. ${ }^{22}$

Mediante la utilización de conceptos como "hegemonía cultural", "intelectuales locales" y "patriarcado democrático", la autora estudió a los campesinos mexicanos y peruanos como sujetos portadores de agencia, de ser, desde una posición de desventaja, constructores de su circunstancia histórica. ${ }^{23}$

Durante los últimos años han surgido fuertes críticas al trabajo 
de Mallon y a la historia cultural norteamericana en general. Particularmente, debemos recordar los duros cuestionamientos esbozados por Stephen Haber para quien la historia cultural subalterna o posmodernista- es en extremo subjetivista. Para él, muchos de sus practicantes son ambivalentes acerca de la noción de la existencia de hechos objetivos, es decir, de que éstos existen independientemente del observador. ${ }^{24}$

Otro aspecto cuestionado por Haber es que uno de los objetivos primordiales de la "nueva historia cultural" es defender un posicionamiento político "progresista", anticolonialista, en el que los sectores oprimidos son rescatados del olvido. El peligro que se corre con este subjetivismo político es excluir a todo historiador que por razones metodológicas ha decidido apartarse del estudio y defensa de los subalternos. ${ }^{25}$ Dicho de otra manera, Florencia Mallon ha sido cuestionada por haber incorporado estructuras mentales personales -como el feminismo- en la explicación de los procesos históricos.

De manera similar a la de Mallon, la participación de las masas campesinas en la construcción del Estado Nacional en México, también fue abordada por Peter Guardino en su libro Peasants, Politics, and the Formation of Mexico's Nacional State. En su opinión los campesinos de México fueron actores fundamentales tanto para la destrucción del Estado colonial español como para la creación del Estado Nacional:

The struggles in which peasants took part in nineteenthcentury Mexico were not battles over whether there was to be a state: they were contests over what the state was to be. This distinction implies that peasants are not, as Eric Wolf asserts, "natural anarchists"; they seek to influence the form of the state and also use existing state institutions for their own ends. ${ }^{26}$

Posteriormente, Eric van Young en La otra rebelión postuló como objetivo primordial de la investigación mostrar, de manera detallada, el papel jugado por las masas populares que nutrieron 
el movimiento independentista durante los años de 1810 a 1821 . Desde la introducción el autor declara su deuda con las líneas historiográficas más importantes en torno a la Independencia de México, las rebeliones campesinas, y los fundamentos de la historia cultural y subalterna que se han desarrollado durante las últimas décadas.

Entre otros muchos aspectos, nos ofrece un perfil estadístico y anecdótico de los insurgentes populares. Mediante un estudio minucioso de documentación archivística, el autor le presta particular atención a los pronunciamientos públicos, los motivos insurgentes y la búsqueda, en muchos casos, del perdón real. Mediante la construcción de una base de datos conformada por 1, 284 personas, el autor nos muestra una aproximación del "perfil social" de los rebeldes. El "rebelde modal" o típico de los primeros años de la lucha insurgente "sería indio, tendría unos treinta años de edad, sería labrador, casado y seguramente lo habrían detenido a una distancia relativamente corta de su casa". También se refiere a la composición, la dinámica y los motivos de la dirigencia local de la insurrección.

El estudio de los "cabecillas" -indígenas y no indígenas- nos muestra las múltiples formas de protesta política y violencia en el mundo rural. Mediante el estudio de registros documentales, el historiador norteamericano hace referencia a la participación de indios caciques y principales en la insurgencia como enlaces naturales entre la gente del pueblo y los rebeldes regionales contrarios al régimen realista. En algunas ocasiones, los hombres que destacaban económica o políticamente en las comunidades pasaban, automáticamente, a ser cabecillas insurgentes durante el periodo de guerra.

La participación de estos "notables indígenas" principalmente fue producto de la defensa de privilegios locales y lograr un posicionamiento político. Sin embargo, la mayoría de los líderes indígenas permanecieron leales al ejército realista. En cuanto a los líderes no indígenas del movimiento armado, los comandantes insurgentes procedían de diversos estratos sociales, casi siempre 
del medio rural. Algunos, como Chito Villagrán, pasaron de ser delincuentes a insurgentes; otros, formaban parte de una clase media rural -como algunos curas-o incluso de un grupo de "élite marginal" provinciana que en ocasiones llegaron a amasar una considerable fortuna y hacer una carrera pública en la nueva nación.

También se analiza el lenguaje de la insurgencia en "todas sus maneras recuperables": lo que se decía en las cantinas, la subversión y los rumores que se convirtieron tumultos populares. La confrontación y las disputas políticas que tenían como medio de propagación la oralidad, sin embargo, Van Young argumenta que también había mucho material propagandístico, tanto del gobierno como de los insurgentes, que se hacía por escrito: decretos formales, panfletos, sátiras y versos sediciosos, informes y cartas, etc. ${ }^{27}$

En general, La otra rebelión complementa el conocimiento que teníamos de la Independencia de México desde una perspectiva, que podríamos llamar, "desde abajo". Frente a una historia que únicamente tomaba en cuenta a los grandes dirigentes y estudiaba solamente los grandes eventos de la rebelión, Eric van Young logra mostrar el prolongado proceso de resistencia cultural de las comunidades rurales, antes sin voz, en un momento de coyuntura. Definitivamente, aunque su influencia en la historiografía mexicana ha sido notable, no hemos percibido aun todos sus alcances.

\section{CAMPESINADO Y TEORÍA MARXISTA}

La transformación del marxismo en México fue mucho más lenta que en el ámbito europeo. En Inglaterra la historia social modificó el enfoque marxista que postulaba que la estructura, invariablemente, determinaba a la superestructura. Para Marx, el modo de producción determinaba los procesos sociales, políticos y espirituales. Así, con el cambio de los fundamentos económicos, tarde o temprano, la superestructura también sería modificada. Hacia los años cincuenta, historiadores y teóricos sociales como Raymon Williams, manifestaron una clara inconformidad ante estos postulados: "The superstructure is a matter of human consciousness, and this is necessarily very complex, not only because of its diversity, but also because it is always historical". ${ }^{28}$ 
Este vuelco hacia lo "ideológico" trastocó los fundamentos economicistas que regían el estudio de las clases subordinadas. Sin embargo, en México, como en gran parte de Latinoamérica, el marxismo ortodoxo, defendido por los teóricos sociales, continuó siendo la guía predilecta dentro de la academia. En general, la influencia de historiadores marxistas reconocidos en la Europa Occidental, muchos de ellos colaboradores de la revista Past and Present fundada en 1952, no tuvo el impacto inmediato que se esperaría. Autores como Christopher Hill, Rodney Hillton, Eric J. Hobsbawm, Lawrence Stone y John Elliot no serían utilizados en la historiografía mexicana hasta finales de los años ochenta. ${ }^{29}$

El materialismo histórico, por lo menos en el caso mexicano, funcionó como instrumento teórico de análisis y como medio de activismo político. Con esta aseveración, no pretendo argumentar que la historia social británica evitara el posicionamiento político, la "historia desde abajo" era, en sí misma, una toma de posición. ${ }^{30}$ Sin embargo, en América Latina, después del triunfo castrista en Cuba, las expectativas revolucionarias y la esperanza de la implantación del comunismo tuvieron una mayor fuerza que en el occidente europeo.

Durante los años sesenta y setenta los estudios sobre el campesinado en México tuvieron un repunte. Una de las razones de este auge fue la multiplicación de revistas especializadas cuyas temáticas estaban guiadas por un marxismo de diferentes tonalidades y preferencias ideológicas: Historia y Sociedad. Revista latinoamericana de pensamiento marxista (1965-1981), fundada por Enrique Semo en 1965 al amparo del PCM; Cuadernos Politicos (1974-1990), con colaboradores como Arnaldo Córdova, Bolívar Echeverría y Carlos Alberto Pereyra Boldrini quienes fomentaron un redescubrimiento del legado gramsciano; y Coyoacán. Revista marxista latinoamericana (1977-1985), creada por el historiador argentino-mexicano de tendencias trotskistas Adolfo Gilly. ${ }^{31}$ Además, se crearon nuevas editoriales como Siglo XXI, Era, Nueva Imagen, El Caballito, que propiciaron la publicación de textos cercanos a la teoría social marxista y a la "izquierda". ${ }^{32}$

En general, durante este periodo, la discusión en torno al campo 
mexicano se dividió en dos grandes facciones: los que argumentaban que en el campo mexicano sobrevivían formas precapitalistas de producción, por lo que era necesario usar el modelo de producción feudal para su estudio y, por otro lado, los que defendían que los campesinos estaban inmersos en el modo de producción capitalista, en este sentido los campesinos eran en realidad proletarios. ${ }^{33}$

Por lo regular, François Chevalier y sus seguidores, han sido incluidos en el primer grupo. Sin embargo, recientes investigaciones han demostrado que en La formación de los latifundios en México, editada por primera vez en 1952, Chevalier nunca postuló que la hacienda mexicana estuviera estructurada por un sistema económico de estilo feudal. En realidad, el historiador francés describió en su trabajo "un proceso singular y específicamente americano de conformación de grandes propiedades territoriales" semejante, en algunos aspectos, al caso europeo pero con marcadas características locales. ${ }^{34}$ Más allá de tomar partido por esta discusión historiográfica, es importante destacar que durante la segunda mitad del siglo XX el texto de Chevalier fue interpretado como un claro ejemplo de la puesta en práctica del modelo de producción feudal.

Por otro lado, con sus matices, Alonso Aguilar Monteverde, Enrique Semo, Roger Bartra, Arturo Warman, entre otros, se ubicarían en la segunda tendencia. Hacia 1968, Monteverde, fuertemente marcado por las teorías dependentistas, afirmaba que el estudio del fenómeno del subdesarrollo en los países atrasados no sólo era necesario "desde un punto de vista científico", sino que era "indispensable también para avanzar en la lucha política que, tarde o temprano, habrá de conducir a su liberación". ${ }^{35}$ Por la misma línea se encontraba Enrique Semo, aunque menos combativo, quien afirmaba que:

El proceso del estudio de los países que se ha dado en llamar subdesarrollados ha demostrado una vez más que la economía sólo es ciencia en la medida en que es ciencia histórica. El origen del atraso así como del desarrollo económico está, no en el clima, la raza o un conjunto de rasgos diversos 
inconexos, sino en las condiciones históricas de la evolución de cada pueblo. ${ }^{36}$

Por otro lado, el caso Roger Bartra es determinante para conocer las posturas marxistas en torno al campo y el campesinado. Además, es patente que fue superando las dos grandes facciones mencionadas arriba. Desde finales de los años sesenta, Bartra llevó a la práctica tanto la teoría marxista como la teoría de la dependencia. Así lo muestra en su estudio El modo de producción asiático. Problemas de la historia de los paises coloniales:

Al explotado y al colonizado el problema no se le presenta solamente en función del por qué debe estar sumido en la miseria, sino de librarse de ella lo más rápido posible. ¿Cómo?37

En su opinión, la respuesta vendría "siempre que se adopte el punto de vista del que está abajo, del explotado y colonizado". Indudablemente, la propuesta de Bartra estaba fuertemente determinada por la esperanza revolucionaria y la liberación de los pueblos oprimidos. En cuanto al estudio de la evolución de los modos de producción, consideraba, al igual que Enrique Semo, que no era recomendable aplicarse como un esquema de etapas cronológicas predeterminadas. En este sentido, declaraba que en la historia de cada pueblo, las combinaciones y el orden de sucesión de los modos de producción no eran dados de antemano:

El estudio concreto de la historia nos da múltiples ejemplos de formas de transición (modo de producción asiático), desarrollo regresivo (el capitalismo en América Latina engendra formas feudales), coexistencia de diferentes modos de producción (la comunidad primitiva con el capitalismo como en México). Saltos de uno o más periodos (del modo de producción asiático al capitalismo en el sureste asiático); de formas precapitalistas al socialismo (Mongolia), sociedades estancadas (ciertas regiones de la India), etc. ${ }^{38}$ 
El análisis clasista y el estudio de la articulación de los modos de producción, le permitió a Bartra afirmar que el eje de la estructura agraria no era la tenencia de la tierra, sino que las formas de propiedad se adaptaban a las peculiaridades de la producción, es decir, de la base económica. ${ }^{39}$ En este sentido, el desenvolvimiento económico no era determinado por la política gubernamental, por el contrario, "la política del Estado corresponde y se adapta a la estructura económica y esta última determina en última instancia a la primera". ${ }^{40}$ Sin embargo, también aceptaba "que los mecanismos de reproducción de las formas de producción no se encuentran exclusivamente en la base económica (especialmente la reproducción de las relaciones de producción) sino también en la superestructura ideológico-política". ${ }^{41}$ Así, podríamos pensar, que durante los años setenta, la rígida conceptualización marxista de base/superestructura fue modificándose paulatinamente para tomar en cuenta, todavía débilmente en México, los factores culturales o "ideológicos" en los estudios sobre el campo y los campesinos.

De hecho, Bartra buscó superar las "dos salidas simplistas" que ya se habían mencionado: la que argumentaba que en el campo mexicano sobrevivían "formas precapitalistas de producción" o feudales y la que, por el contrario, veía la existencia del modo de producción capitalista en los campesinos, convirtiéndolos en proletarios. En su opinión, en México coexistían un sector desarrollado y uno subdesarrollado, que generaban factores tanto negativos como positivos en el proceso de acumulación de capital:

La existencia de un sector subdesarrollado no capitalista da a los comerciantes capitalistas la posibilidad de obtener superganancias enormes y proporciona a los industriales y agricultores capitalistas una reserva de fuerza de trabajo barata. Pero, por otro lado, el mantenimiento de esta situación restringe el mercado interno a la larga y ocasiona en alguna etapa enormes inversiones de capital en obras de infraestructura con objeto de capitalizar al sector atrasado. ${ }^{42}$ 
Los sectores campesinos "semicapitalistas", como los llama Bartra, sufrían de explotación ya que se "abonan a sí mismos el salario", y "una parte del trabajo sobrante es regalado a la sociedad y no entra para nada en la regulación de los precios de producción ni en la formación del valor". ${ }^{43}$ Dicho con otras palabras, el autor aseguraba que la posibilidad de que los agricultores capitalistas se apropiasen de elevadas ganancias provenía de la existencia del usufructo directo de la tierra (propiedad privada o ejido). Cuando el agricultor era al mismo tiempo el propietario o ejidatario, no pagaba renta alguna por la tierra, y de hecho se guardaba para sí, como ganancia extraordinaria, el valor de la renta de ésta. ${ }^{44}$ Así, el campesino aun siendo dueño de los medios de producción, sufría del despojo de una parte considerable de su trabajo por parte de la sociedad.

Arturo Warman, desde la antropología, también propuso algunos lineamientos interpretativos con relación a la resistencia rural. Aunque, al parecer, su investigación estuvo fuertemente influenciada por autores como Eric Wolf, Marshall Sahlins, Eric Hobsbawm, Clifford Geertz y Barrington Moore, permaneció fiel al materialismo histórico de viejo cuño. Estudió la "persistencia campesina y las estrategias de supervivencia" en el estado de Morelos ante el embate del Estado mexicano y "el sistema capitalista industrial mundial en su más amplio sentido". Para él, el Estado burgués era "el principal agente de la explotación", el que imponía "las condiciones generales para la distribución de los recursos" y los campesinos, víctimas del sistema mundial y la lucha de clases, sólo conservaban, "y a duras penas, lo suficiente para vivir de la manera más frugal y sin posibilidad de ahorro ni acumulación" ${ }^{45}$ Era claro, en su opinión, que "para ser modernos" los campesinos "habían tenido que hacerse más tradicionales". Así, el trabajador rural se nos muestra como un individuo incapaz de acción y obligado, por el sistema, a ir en contra de su propia naturaleza:

Tienen que sembrar maíz que van a comer, realizar gastos ceremoniales, hacerse de compadres, establecer relaciones recíprocas para el intercambio directo, no capitalista, de trabajo y de recursos productivos. ${ }^{46}$ 
Como hemos estado argumentando, es evidente que los marxistas mexicanos no tomaban en cuenta la costumbre y la tradición en el comportamiento campesino. Hacia 1980, Leticia Reina con su trabajo Las rebeliones campesinas en México, mostró, en cierta medida, algunos cambios de perspectiva. Postuló que el campesinado mexicano, durante el siglo XIX, desempeñó “el papel de fuerza principal en los procesos de cambio y consolidación del estado nacional", sin embargo, también aclaró que su perspectiva era la de la lucha de clases. ${ }^{47}$ Así, proponía que el campesino, más allá de su papel de víctima, había jugado un papel preponderante como actor político. Sin embargo, el reconocimiento de la subsistencia y el autoconsumo como manifestaciones culturales netamente campesinas, son propuestas planteadas por la "economía moral" que sólo tendrían eco en México hasta la segunda mitad de los años ochenta.

\section{LA ECONOMÍA MORAL: LA CULTURA COMO DETERMINANTE}

Después de la etapa marxista en México se manifestaron cambios significativos en la forma de abordar el problema campesino $y$ sus formas de resistencia. Las nuevas propuestas provinieron, como comúnmente ocurre, de algunos investigadores extranjeros interesados en el pasado mexicano. Por ejemplo, la imagen feudal de la hacienda en el siglo XIX fue fuertemente cuestionada. Investigadores como John Womack, Jan Bazant, David Brading, entre otros, realizaron grandes esfuerzos por seńalar la naturaleza comercial de las haciendas y su afán de introducir modernos métodos de cultivo para ser más competitivas en el mercado. Por consiguiente, como lo afirmó David Brading, no fue el feudalismo, sino una forma más intensa de capitalismo agrícola, lo que perjudicó a los campesinos mexicanos. ${ }^{48}$

Al mismo tiempo que se despejaban algunas dudas sobre el comportamiento económico de las haciendas mexicanas, los investigadores sociales manifestaron un fuerte interés por las rebeliones y descontentos populares. Además del ya mencionado John Womack y su Zapata and the Mexican Revolution (1968), 
T. G Powell se abocó a los efectos de las Leyes de Reforma en algunas comunidades campesinas de Hidalgo, Puebla y la ciudad de México. Ante el despojo de tierras por hacendados y terratenientes, se produjeron una serie de rebeliones indígenas que muestran las formas de resistencia campesina ente el embate del liberalismo decimonónico. ${ }^{49}$

Alan Knight, antes de publicar su obra más significativa The Mexican Revolution (1986), ya manifestaba su interés por los campesinos durante la Revolución. En su opinión, hacia 1900 los salarios reales en la agricultura y en la industria disminuyeron precipitadamente $\mathrm{y}$, hacia finales de la década, la depresión económica, el desempleo y las malas cosechas contribuyeron a fomentar el descontento social. Además, dejó en claro que, en contra de antiguas interpretaciones que veían al pueblo como claramente dependiente e ingenuo, el campesino tenía capacidad de acción e iniciativa. $^{50}$

Por la misma época, el norteamericano Eric Van Young, basado en Eric Wolf, argumentó que las prácticas comunales de resistencia indígena ante el proceso de "proletarización", en la región de Guadalajara durante la época colonial, mostraban la capacidad de respuesta de estos grupos:

For those villaje-dwellers who managed to maintain their economic footing in the autonomous Indian communes, often in combination with rural wage labor or some other nonfarming activity, a precarious life with a degree of autonomy was clearly preferable to decent into the ranks of the growing rural proletariat. ${ }^{51}$

Sin embargo, fue hasta la aparición del libro de John Tutino, De la insurrección a la Revolución en México (1986), cuando realmente se inició, en el ámbito académico mexicano, la discusión en torno a las rebeliones populares con la economía moral, y otros postulados teóricos, como trasfondo. ${ }^{52} \mathrm{El}$ trabajo de Tutino recogió la tradición anglosajona más influyente desde los años sesenta con respecto a 
los movimientos sociales. De las obras de Barrington Moore, Social Origins of Dictatorship and Democracy (1966) e Injustice: The Social Bases of Obedience and Revolt (1978), destacó la importancia que se le da a los campesinos al explicar los diversos desenlaces políticos de las transformaciones hacia el modo de vida urbanizado e industrializado en Inglaterra, Francia, los Estados Unidos, China, Japón y la India.

En opinión de Tutino, Eric Wolf es otro de los autores indispensables para conocer el impacto y los motivos de las rebeliones campesinas. Principalmente, se centró en Peasant Wars of the Twentieth Century (1969), que aborda la importancia de la violencia agraria en las luchas revolucionarias de México, Rusia, China, Vietnam, Argelia y Cuba. Tutino hace hincapié en que estos dos estudios colocaron a los campesinos en el centro de la atención. Moore y Wolf coinciden en resaltar que los campesinos se volvieron más levantiscos conforme la expansión del capitalismo comercial iba minando los arraigados modos de vida agraria. De alguna manera, "el capitalismo perforó la túnica de la costumbre". ${ }^{53}$

No obstante, el trabajo más influyente para el estudio del campesinado fue, sin lugar a dudas, el de John Scott, The Moral Economy of the Peasant (1976). Como ya lo mencioné al inicio del texto, Scott tomó el concepto de "economía moral” de E. P. Thompson quien lo había utilizado para estudiar a los obreros británicos de finales del siglo XVIII y principios del XIX. Scott, por su parte, logró consolidar esta perspectiva en el ámbito campesino del sureste de Asia. En su opinión, el campesino veía el mundo a través de un prisma moral en el que la subsistencia se concebía como el derecho humano básico. Deduce que la denegación de ese derecho es la raíz de los levantamientos campesinos:

Cuando la subsistencia del campesino se torna insegura, cuando el sustento disponible cae por debajo del umbral mínimo de supervivencia en repetidos años de crisis, es cuando los campesinos se aprestan a correr el riesgo de la insurrección. ${ }^{54}$ 
Guiado por estas propuestas, Tutino, para explicar cambios sociales complejos, propuso cuatro características básicas. La primera se conforma de las condiciones materiales, es decir, del nivel de vida de la población que se pretende estudiar. Las otras tres "son más cualitativas y describen el impacto de las relaciones de poder sobre la vida de los pobres del campo": la autonomía, la seguridad y la movilidad relativas de las familias agrarias. ${ }^{55}$

La Autonomía refleja la capacidad de la gente para producir en forma independiente lo que necesita para subsistir. En general el campesino es el más autónomo de la gente del campo, pues por definición produce directamente la mayoría de los bienes para su subsistencia. Pero las diferencias en autonomía son igualmente importantes dentro de un mismo grupo de los que generalmente se clasifican como campesinos. Por ejemplo, algunos son dueños de tierras extensas, fértiles o bien irrigadas; otros, por lo contrario, han de rentar la tierra y por consiguiente son menos autónomos.

Seguridad es la capacidad de alcanzar la subsistencia de modo uniforme, de confiar en la posibilidad de alcanzar un nivel de vida, mínimamente aceptable, a lo largo de un futuro predecible. Entre los campesinos la seguridad cambia según la región y la calidad de las tierras, las condiciones de acceso a las tierras, la regularidad de las lluvias y muchas otras consideraciones.

Es indudable que todo mundo valora la seguridad en cierta medida, pero se vuelve importantísima, a veces una evidente obsesión, entre los pobres del campo cuya vida está sujeta a dependencia. ${ }^{56}$

Finalmente, la Movilidad es entendida como la capacidad de elegir entre diversos medios de obtener la subsistencia. Así, la autonomía, la seguridad y la movilidad están ligadas a la forma que la gente tiene de ganarse el sustento. ${ }^{57}$ William Taylor en Drinking, Homicide, and Rebellion in Colonial Mexican Villages (1979), confirma lo expuesto por Tutino, ya que afirma que para los campesinos comunales era esencial conservar la autonomía local 
de subsistencia y la independencia de gobierno. A fines de la época colonial protestaban, armaban motines y rebeliones esporádicas en cuanto se veía amenazada esa autonomía de los pueblos. ${ }^{58}$

Hacia finales de la década de los ochenta, Friedrich Katz reunió a un grupo de estudiosos de diversos países en Ixtapa, México y en la ciudad de Nueva York, para presentar y comparar sus hallazgos en relación con los levantamientos rurales en México desde el siglo XVI hasta el XX. Entre los investigadores reunidos para aquella serie de conferencias se encontraban, además del mencionado F. Katz, Raymond Buve, John H. Coatsworth, Romana Falcón, John M. Hart, Evelyn Hu-DeHart, Herbert J. Nickel, Enrique Montalvo Ortega, John Tutino, Arturo Warman, Eric Van Young, entre otros especialistas de la historia social y rural en México.

En opinión de Katz, los principales problemas que se discutieron en aquella ocasión giraron en torno cuestionamientos como ¿Qué grupos del campo tendían más a la revuelta? ¿Cuáles eran los motivos de la sublevación? ¿Qué tan importante era la cuestión de la tierra o los derechos del agua? ¿Cuánto pesaba la cuestión de la autonomía local y el nombramiento de funcionarios locales?5 Estas y otras interrogantes guiaron la discusión que permearía, por lo menos durante la siguiente década, los planteamientos metodológicos y teóricos de la investigación historiográfica sobre el campo mexicano y sus actores sociales.

En su ensayo John H. Coatsworth comparó los levantamientos rurales de México (durante la época colonial) con otras regiones del continente como Perú y clasificó las sublevaciones de acuerdo a "patrones de acción colectiva ilegal": las invasiones de tierras, los motines o levantamientos de pueblos y las guerras de castas. ${ }^{60}$ John Tutino, por su parte, analizó los movimientos campesinos en Chalco durante el año de 1868, sin embargo, lo más importante en su propuesta es preguntarse por qué existió escasa violencia campesina, pese a la extrema desigualdad, en la época colonial. Concluye, que la conquista, la coerción y la desigualdad (incluso la crueldad) no bastan para explicar la rebeldía rural en México. Durante el siglo XIX, en cambio, las relaciones sociales rurales 
pasaron de la explotación estable y simbiótica al enfrentamiento violento. El poder mediador del Estado colonial quedó eliminado y las élites decimonónicas de Chalco, ante la ruina financiera, creyeron hallar soluciones en la innovación agrícola. Estas medidas, como era de esperarse, causaron la pérdida de la autonomía comunal y, por consiguiente, el descontento popular y el claro enfrentamiento. ${ }^{61}$

Hasta aquí los aportes de autores como Eric Van Young, Alan Knight, John Tutino, Friedrich Katz, John H. Coatsworth, entre otros, que replantearon los enfoques interpretativos con relación al campo mexicano y la rebelión de las clases desposeídas. Pero, ¿cuál fue la recepción de estas posturas en los historiadores mexicanos? Romana Falcón, una de las investigadoras más prominentes en cuanto al estudio de los grupos subalternos de las últimas décadas, realizó hacia finales de los años setenta una serie de investigaciones que prepararon el camino de su posterior interés en "la historia desde abajo". Inicialmente, presentado como tesis de maestría en El Colegio de México hacia 1975, su libro El agrarismo en Veracruz. La etapa radical (1928-1935) buscó ir más allá de una historia general del movimiento campesino. Su interés primordial fue el estudio de grupos con características autonomistas frente a la construcción del sistema político posrevolucionario. Para la autora, la historia contemporánea de México podía entenderse como la lucha entre el poder central -el del Ejecutivo-y aquellas fuerzas que pretenden ampliar los límites del pluralismo buscando una mayor autonomía. ${ }^{62}$

Posteriormente en el libro Revolución y caciquismo. San Luis Potosi, 1910-1938, producto de su tesis doctoral en la Universidad de Oxford, ${ }^{63}$ es patente que, aunque sus intereses agraristas pasaron a un segundo término y se concentró en el cacicazgo y el clientelismo postrevolucionario, inició su interés por James C. Scott. Las referencias a este teórico social, como hemos estado argumentando, son determinantes para entender la transformación de los estudios sobre los campesinos en México. ${ }^{64}$

Iniciada la década de los noventa, el derrumbamiento del llamado "socialismo real" propició, de manera acelerada, un cambio de perspectiva en los estudios sobre las clases desposeídas. Romana 
Falcón, y otros estudiosos, se han visto fuertemente influenciados por los estudios subalternos o postcoloniales en las líneas propuestas por autores como E. P. Thompson, James C. Scott y Florencia Mallon, entre muchos otros. ${ }^{65}$ Así lo muestra su artículo "Descontento campesino e hispanofobia. La tierra caliente a mediados del siglo XIX” publicado en Historia Mexicana en el año de 1995. Falcón menciona en su texto, parece que por primera vez, la escuela teórica de E. P. Thompson y Scott con referencia a los actos de resistencia de los campesinos: "entre ellos, la falsa aceptación de jerarquías y orden moral, el incumplimiento de normas sociales y de trabajo, lentitud en las labores asignadas, pequeños robos, provocaciones, desafíos y retos, y, en una escala más agresiva, sabotajes, incendios provocados y otros". ${ }^{66}$

En la última década, ha reflexionado sobre las principales vías, formales e informales, mediante las cuales los pobres y marginados del campo en el México de la República Restaurada (1867-1876), resistieron al statu quo, en la mayoría de los casos, de manera no abiertamente revolucionaria:

Quienes ocupan los últimos peldańos de la jerarquía social se resisten y desafían su destino, en general de manera velada, en un plano simbólico o de pequeñas resistencias personales y cotidianas que no requieren organizaciones formales ni planes y pronunciamientos públicos. De hecho, los propios sectores subordinados buscan que sus acciones y omisiones no sean interpretadas como retos abiertos, claros y programados. ${ }^{67}$

Así, Romana Falcón ha entrado de lleno en las discusiones planteadas por Scott en dos obras fundamentales: Weapons of the Weak y Domination and the arts of resistance. ${ }^{68}$ Cuando la resistencia, la insubordinación y la protesta pública, lo "oculto" se vuelven visibles, la inconformidad popular, antes latente pero silenciosa, aparece, en el momento menos pensado, como "acto simbólico" o, en su caso extremo, como violencia desatada. De esta manera, el consenso social ha sufrido una ruptura, quizás, irreversible. 


\section{CONSIDERACIONES FINALES}

En este trabajo se ha mostrado cómo hacia la segunda mitad del siglo XX la historia social británica, la escuela de los Annales y la antropología estuvieron siempre presentes en el giro cultural que tomó como objeto de estudio a las clases populares o subalternas. Así, la New Cultural History ha continuado, desde los años noventa, la fuerte tradición legada por los estudios poscoloniales iniciados en la India y continuados por otras regiones que se han considerado históricamentezonas periféricas dominadas por el poder hegemónico.

En el caso de la historiografía mexicana, el análisis sobre la realidad campesina pasó de un marxismo duro, practicado desde los años sesenta hasta finales de los ochenta, a una lenta pero firme renovación de los estudios sociales. La transformación provino desde el propio marxismo con autores como Raymond Williams y E. P. Thompson, quienes, sin abandonar el interés por los grupos desposeídos, dieron un vuelco hacia el estudio de la tradición, la costumbre, es decir, la cultura popular en general. Esta nueva perspectiva, inicialmente aplicada a los obreros, fue adaptada por James Scott para utilizarla en el ámbito rural. La "economía moral" propia de los sectores campesinos para resistirse al embate capitalista de los tiempos modernos, fue retomada por diversos investigadores interesados en llegar a un mejor entendimiento del hombre de campo.

En el caso concreto de México, las discusiones hacia finales de la década de los ochenta sentaron las bases para una nueva comprensión de estos fenómenos. No hubo vuelta atrás. La cultura fue tomada como parte primordial del comportamiento campesino, sin embargo, esto no significó que la economía se dejara de lado, por el contrario, la nueva perspectiva permitió repensar a los actores productivos y económicos con otros ojos.

En la actualidad, considero que estos postulados dicotómicos: cultura subalterna/cultura de élite, centro/periferia, son cada vez más cuestionados por los investigadores sociales. Es claro que detrás de estas categorías existe una toma de posición política. La defensa de los marginados, dentro de la historiografía contemporánea, conlleva 
reconocer que existe un "arriba y un abajo". Ante estas posturas, hay quienes aseguran, siguiendo a Michael Foucault, que el poder no cuenta con un solo centro, sino que es múltiple y heterogéneo. Nadie es el titular de él: "el punto en el que el poder encuentra el núcleo mismo de los individuos, alcanza su cuerpo, se inserta en sus gestos, sus actitudes, sus discursos, su aprendizaje, su vida cotidiana”. ${ }^{69}$ Así, si negamos la existencia de un centro de poder, estaríamos afirmando que no existen dominadores y dominados. Esta afirmación nos llevaría a cuestionar la verticalidad epistemológica que ha guiado a los estudios sociales, optando por una horizontalidad metodológica.

\section{Notas}

1 Un resumen del presente artículo se publicó en la revista Encheridion, número X, julio-diciembre del 2018, pp. 38-43

${ }^{2}$ Aquí hago alusión al trabajo de Elías José Palti, La nación como problema. Los historiadores y la "cuestión nacional", Buenos Aires, FCE, 2006. El texto estudia el surgimiento, en el siglo XIX, del interés por la "nación" como problema historiográfico. Al respecto, también desde la historia intelectual, es interesante el libro coordinado por Carlos Illades y Rodolfo Suárez, México como problema. Esbozo de una historia intelectual, México, UAM/Siglo XXI, 2012.

${ }^{3}$ Lynn Hunt, "Introduction: History, Culture, and Text", en The New Cultural History, Berkeley, University of California Press, 1989 , p. 1-2.

${ }^{4}$ E. P. Thompson, La formación histórica de la clase obrera. Inglaterra, 1780-1832, Barcelona, LAIA, 1977.

5 Carlos Illades, "Introducción”, en E. P. Thompson, Historia Social y Antropología, México, Instituto Mora, 1994, p. 14.

6 E.P. Thompson, "Folklore, antropología e historia social" (1976), Historia Social y Antropología, México, Instituto Mora, 1994, p. 56.

7 bid., p. 60. 
${ }^{8}$ E.P. Thompson, Customs in common, New York, New Press, 1993

${ }^{9}$ E.P. Thompson, "The Moral Economy of the English Crown in the eighteenth century", en Past and Present, número 50, 1971, p. 76-136.

${ }^{10}$ Eric Van Young, "Nueva introducción a la segunda edición de La ciudad y el campo en el México del siglo XVIIr", en Economía, politica y cultura en la historia de México. Ensayos historiográficos, metodológicos y teóricos de tres décadas, San Luis Potosí, El Colegio de San Luis/El Colegio de la Frontera Norte/ El Colegio de Michoacán, 2010, p. 110.

${ }^{11}$ James C. Scott, The Moral Economy of the Peasant. Rebellion and subsistence in southeast Asia, New Haven, Yale University Press, 1976, p. 13.

${ }^{12}$ José Luis Molina y Hugo Valenzuela, Invitación a la antropología económica, Barcelona, Bellaterra, 2007, p. 128.

13 Jacques Le Goff y Pierre Nora (dir.), Hacer la historia, Barcelona, Editorial LAIA, 1985, p. 95.

14 Roger Chartier, "El mundo como representación", en $E l$ mundo como representación. Estudios obre historia cultural, Barcelona, Gedisa, 2005, p. 45-62.

${ }^{15}$ Guillermo Zermeño, "Condición de subalternidad, condición portmoderna y saber histórico. ¿Hacia una nueva forma de escritura de la historia?", en Historia y Grafía, número 12, año 1999, p. 1147.

${ }^{16}$ Ranajit Guha, "La muerte de Chandra", en Historia y Grafía, número 12 , año 1999 , p. 49-86.

17 Dipesh Chakrabarty, "Historias de las minorías, pasados subalternos", en Historia y Grafía, número 12, año 1999, p. 87-111.

18 Dipesh Chakrabarty, "La poscolonialidad y el artilugio de la historia: ¿Quién habla en nombre de los pasados "indios"? en Pasados Poscoloniales, México, El Colegio de México, 1999, p.623658 y Dipesh Chakrabarty, "Radical Histories and Question of Enlightenment Rationalism: Some Recent Critiques of Subaltern Studies" en Vinayak Chaturvedi (edited), Mapping Subaltern Studies 
and the Postcolonial, London, Verso, 2000, p. 256-280.

19 Eric Van Young, "La nueva historia cultural llega al México Antiguo", en Economia, politica y cultura en la historia de México. Ensayos historiográficos, metodológicos y teóricos de tres décadas, San Luis Potosí, El Colegio de San Luis/El Colegio de la Frontera Norte/ El Colegio de Michoacán, 2010, p. 436.

20 Florencia Mallon, Campesino y Nación. La construcción de México y Perú poscoloniales, traducción de Lilyán de la Vega, CIESAS, El Colegio de San Luis, El Colegio de Michoacán, México, 2003.

${ }^{21}$ Tulio Halperín Dongui, "Campesinado y nación", en Luis Gerardo Morales Moreno (compilador), Historia de la historiografía contemporánea (de 1968 a nuestros dias)", México, Instituto Mora, 2005, p. 404-405.

${ }^{22}$ Mallon, Campesinado..., op.cit., p. 83.

${ }^{23}$ Ibid., p. 85-95.

${ }^{24}$ Stephen Haber, "Anything Goes: Mexico's "New” Cultural History", en The Hispanic American Historical Review, volumen 79, número 2, 1999, p. 310.

${ }^{25}$ Una visión más sosegada de estas cuestiones la tiene Alan Knight, quien coincide con Haber en algunos puntos pero considera que su posición es "positivista”. Además, reconoció que la historia cultural ha sido innovadora en varios aspectos. Alan Knight, "Subalterns, signifiers, and statistics: Perspectives on Mexican Historiography", en Latin American Research Review, volume 37, número 2, 2002, p. 153-156.

${ }^{26}$ Peter Guardino, Peasants, Politics, and the Formation of Mexico's Nacional State, Stanford, Staford University Press, 1996, p. 4.

${ }^{27}$ Eric van Young, La otra rebelión. La lucha por la independencia de México, 1810-1821, México, FCE, 2006 (2001).

${ }^{28}$ Raymond Williams, "Marxism and Culture", en Culture and Society: 1780-1950, New York, Columbia University Press, 1983 (1958), p. 266.

${ }^{29}$ Carlos Illdes, La inteligencia rebelde. La izquierda en el debate público en México. 1968-1989, México, Oceano, 2011, p. 49-54.

30 Como lo ha mostrado Alejandro Estrella González, el 
compromiso político de Thompson constituye el fondo experiencial que lo llevó a adoptar el "punto de vista de los dominados". Alejandro Estrella González, "Las ambigüedades de la historia desde abajo de E. P. Thompson: las herramientas del historiador entre la forma, el compromiso político y las disposiciones sociales", en Signos Históricos, número 22, julio-diciembre, 2009, p. 76-108.

${ }^{31}$ Carlos Illades, La inteligencia rebelde, op.cit.

${ }^{32}$ Barry Carr, La izquierda mexicana a través del siglo XX, México, Era, 1996, p. 244-447.

${ }^{33}$ Eric Van Young, "La historia rural de México desde Chevalier: historiografía de la hacienda colonial", en Economía, politica y cultura en la historia de México. Ensayos historiográficos, metodológicos y teóricos de tres décadas, San Luis Potosí, El Colegio de San Luis/ El Colegio de la Frontera Norte/ El Colegio de Michoacán, 2010, p. 3-84 y Eric Van Young, "Historiografía rural de América Latina desde la conquista hasta el presente" en Economía, politica y cultura en la historia de México. Ensayos historiográficos, metodológicos y teóricos de tres décadas, San Luis Potosí, El Colegio de San Luis/El Colegio de la Frontera Norte/ El Colegio de Michoacán, 2010, p. 141-172.

${ }^{34}$ Salvador Álvarez Suárez, "El latifundio y la historia económica novohispana. Por una relectura de la obra de François Chevalier", en Letras Históricas, número 7, otońo 2012-invierno 2013, p. 37.

${ }^{35}$ Alonso Aguilar Monteverde, Dialéctica de la economía mexicana, México, Editorial Nuestro Tiempo, 1983 (1968), p. 13.

${ }^{36}$ Enrique Semo, Historia del capitalismo en México, México, SEP/ERA, 1987 (1973), p. 13.

${ }^{37}$ Roger Bartra, El modo de producción asiático. Problemas de la historia de los países coloniales, México, Era, 1975 (1969), p. 11.

38 Roger Bartra, "Sociedades precapitalistas" en Historia y Sociedad, año I, número 3, otońo 1965, pp. 35-42, citado por Enrique Semo, Historia del capitalismo en México, Op.cit, p. 19.

${ }^{39}$ Roger Bartra, Estructura agraria y clases sociales en México, México, Era, 1974, p. 9-10.

${ }^{40}$ Ibid. p. 11. 
${ }^{41}$ Ídem.

${ }^{42}$ Ibid., p. 31-32.

${ }^{43}$ Ibid., p. 57.

${ }^{44}$ Ibid., p. 68.

${ }^{45}$ Arturo Warman, ... Y venimos a contradecir. Los campesinos de Morelos y el estado nacional, México, La Casa Chata, 1978 (1976), p. 15-16.

${ }^{46}$ Ídem.

47 Leticia Reina, Las rebeliones campesinas en México (18191906), México, Siglo XXI, 1984 (1980), pp. 13-15.

48 David Brading, "Introducción. La política nacional y la tradición populista", en David Brading, Caudillos y campesinos en la Revolución Mexicana, México, FCE, 1996 (1980), p. 26-27.

49 T. G. Powell, El liberalismo y el campesinado en el centro de México, 1850 a 1876, México, SEP, 1974.

50 Alan Knight, "Caudillos y campesinos en el México revolucionario, 1910-1917”, en David Brading, Op.cit, p. 33-34.

${ }^{51}$ Eric Van Young, "Conflict and Solidarity in Indian Village Life: The Guadalajara Region in the late Colonial Period", $H A H R$, volumen 64, número 1, febrero de 1984, p. 79.

52 En este mismo año también apareció la influyente obra de Brian R. Hamnett, Roots of Insurgency. Mexican regions, 17501824. El texto describe las tenciones sociales en una variedad de regiones. Aunque, al igual que Tutino, también toma en cuenta a los sectores marginales del campo mexicano su análisis se extiende a grupos sociales que lideraron el movimiento insurgente. Véase Peter Guardino, "Los campesinos mexicanos y la guerra de Independencia. Un recorrido historiográfico", en Tzintzun, número 51, enero-junio de 2010, p. 20-21.

53 John Tutino, De la insurrección a la Revolución en México. Las bases sociales de la violencia agraria 1750-1940, México, ERA, 1990 (1986), p. 25-26.

${ }^{54}$ Ibid. p. 29.

55 Ibid. p. 35.

${ }^{56}$ Ibid., p. 37. 
${ }^{57}$ Ibid., p. 38.

${ }^{58}$ Ibid., p. 41.

${ }^{59}$ Friedrich Katz, "Introducción: Las revueltas rurales en México", en Friedrich Katz (comp.), Revuelta, Rebelión y Revolución. La lucha rural en México del siglo XVI al siglo XX, México, Siglo XXI, 1999 (1988), tomo I, p. 10.

${ }^{60}$ John H. Coatsworth, "Patrones de rebelión rural en América Latina: México en una perspectiva comparativa”, en Friedrich Katz (comp.), Revuelta, Rebelión y Revolución, p. 27-61.

${ }^{61}$ John Tutino, "Cambio social agrario y rebelión campesina en el México decimonónico: el caso de Chalco, en Friedrich Katz (comp.), Revuelta, Rebelión y Revolución, p. 94-134.

${ }^{62}$ Romana Falcón, El agrarismo en Veracruz. La etapa radical (1928-1935), México, El Colegio de México 1977, p. 3-4.

${ }^{63}$ Romana Falcón, Revolución y caciquismo. San Luis Potosí, 19101938, México, El Colegio de México, 1984.

${ }^{64}$ El texto de James C. Scott que cita Romana Falcón es "Patron client politics and political change in Southeast Asia", en American Political Science Review, 1971.

${ }^{65}$ Principalmente cita las siguientes obras: Florencia Mallon, "Los campesinos y la formación del Estado en el México del siglo XIX: Morelos, 1848-1858”, Op.cit, con relación a la pérdida de derechos ancestrales que ponen en peligro las capacidades de sobrevivencia campesina; E. P. Thompson, Tradición, revuelta y conciencia de clase (1979) y James Scott, Weapons of the Weak. Everyday Forms of Peasant Resistence (1985).

66 Romana Falcón, "Descontento campesino e hispanofobia. La tierra caliente a mediados del siglo XIX", en Historia Mexicana, volumen XLIV, número 3, 1995, p. 484.

${ }^{67}$ Romana Falcón, "El arcoíris de la resistencia entre los pobres del campo en México" en Historia desde los márgenes. Senderos hacia el pasado de la sociedad mexicana, México El Colegio de México, 2011 (2002), p. 53-54.

${ }^{68}$ James Scott, Weapons of the Weak. Everyday Forms of Peasant Resistence, New Haven, Yale University Press, 1985 y Domination 
and the arts of resistance. New Haven, Yale University Press, 1990.

${ }^{69}$ Michel Foucault, Microfisica del poder, Madrid, La Piqueta, 1992 (1972), p. 89

Fecha de Recepción: 16 octubre de 2019

Fecha de Aceptación: 15 marzo de 2020

Versión FinAL: 10 de abril de 2020 